\title{
Characterization of Porcine Ventral Mesencephalic Precursor Cells following Long-Term Propagation in 3D Culture
}

\author{
Pia S. Jensen, ${ }^{1}$ Lise Lyck, ${ }^{1,2}$ Pia Jensen, ${ }^{1}$ Jens Zimmer, ${ }^{1}$ and Morten Meyer ${ }^{1}$ \\ ${ }^{1}$ Department of Neurobiology Research, Institute of Molecular Medicine, University of Southern Denmark, \\ 5000 Odense C, Denmark \\ ${ }^{2}$ Coloplast Danmark, Holtedam 1-3, 3050 Humleboe, Denmark
}

Correspondence should be addressed to Morten Meyer, mmeyer@health.sdu.dk

Received 21 March 2012; Accepted 4 September 2012

Academic Editor: Cesario Borlongan

Copyright (C) 2012 Pia S. Jensen et al. This is an open access article distributed under the Creative Commons Attribution License, which permits unrestricted use, distribution, and reproduction in any medium, provided the original work is properly cited.

\begin{abstract}
The potential use of predifferentiated neural precursor cells for treatment of a neurological disorder like Parkinson's disease combines stem cell research with previous experimental and clinical transplantation of developing dopaminergic neurons. One current obstacle is, however, the lack of ability to generate dopaminergic neurons after long-term in vitro propagation of the cells. The domestic pig is considered a useful nonprimate large animal model in neuroscience, because of a better resemblance of the larger gyrencephalic pig brain to the human brain than the commonly used brains of smaller rodents. In the present study, porcine embryonic (28-30 days), ventral mesencephalic precursor cells were isolated and propagated as free-floating neural tissue spheres in medium containing epidermal growth factor and fibroblast growth factor 2. For passaging, the tissue spheres were cut into quarters, avoiding mechanical or enzymatic dissociation in order to minimize cellular trauma and preserve intercellular contacts. Spheres were propagated for up to 237 days with analysis of cellular content and differentiation at various time points. Our study provides the first demonstration that porcine ventral mesencephalic precursor cells can be long-term propagated as neural tissue spheres, thereby providing an experimental 3D in vitro model for studies of neural precursor cells, their niche, and differentiation capacity.
\end{abstract}

\section{Introduction}

Parkinson's disease (PD) is characterized by a progressive loss of dopaminergic neurons in the substantia nigra in the ventral mesencephalon (VM). The disease is clinically characterized by serious motor dysfunctions, including muscle rigidity, tremor, bradykinesia, and sometimes akinesia [1]. A number of experimental animal and clinical studies using human fetal VM tissue have suggested that intrastriatal transplantation of dopaminergic neurons may be an effective treatment for patients with PD [2-4]. However, low availability of human foetal tissue, ethical concerns related to its procurement and use, limited survival and integration of the grafted dopaminergic neurons, and the highly variable developmental stage of the donor tissue have restricted the clinical application [5].

A number of studies have characterized two neurogenic areas in the mammalian brain, the subventricular zone (SVZ) lining the lateral ventricles [6] and the dentate gyrus of the hippocampus [7]. The existence of precursor cells with neurogenic potential has also been reported for the developing [8-10] and to some degree the adult [11-15] ventral midbrain. Such neural precursor cells expanded in vitro are considered a potential source of cells for cell replacement in PD [16]. However, generation of functional dopaminergic neurons from this cell source has proven difficult [17], and therefore there is a need to develop experimental protocols and models for studies of precursor cell proliferation and dopaminergic differentiation.

Usually cultures of neural precursor cells are established by initial mechanical or enzymatic dissociation as well as enzymatic dissociation during cell passaging. The enzymatic dissociation may lead to stripping of proteins on the cell surface and in this way disrupt pathways for intracellular signal transduction, intercellular communication, and cell migration, which are important for cell development, proliferation, and differentiation [18]. In order to avoid mechanical and enzymatic dissociation and to preserve an 


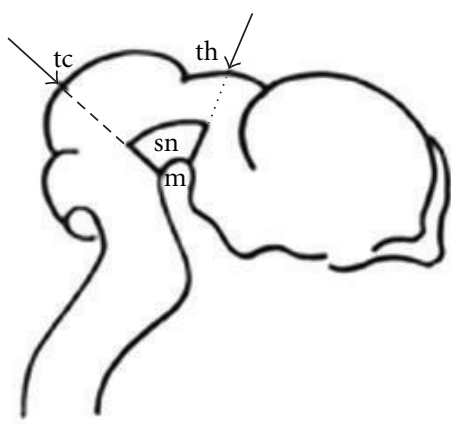

(a)

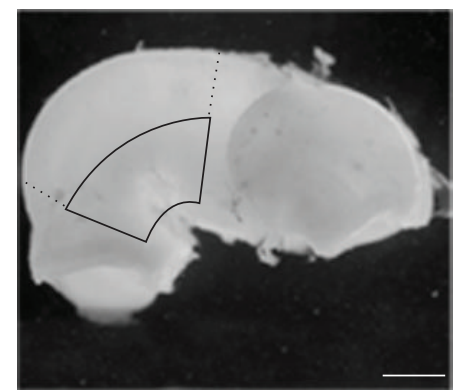

(b)

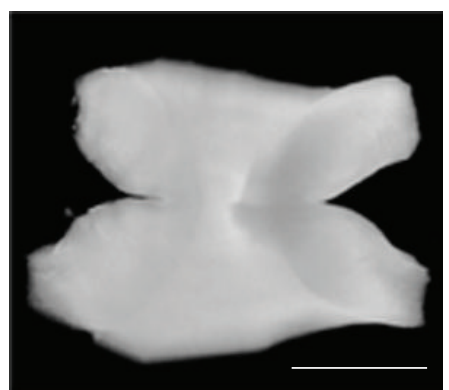

(c)

Figure 1: Dissection of porcine embryonic (E28-30) ventral mesencephalon (VM). (a) Lateral perspective showing the angle of the first two cuts of the dissection, with imaginary lines (arrows) intersecting the dorsal surface of the tectum (tc) and the thalamus (th) (from Dunnett and Bjorklund, 1992). (b) Brain of a 28-day-old embryo with the dissection lines from (a) marked. The area encircled by solid lines represents the VM. (c) The ventral surface of the isolated VM explant. Scale bars: $500 \mu \mathrm{m}$.

organotypic intercellular microenvironment during propagation of neural precursor cells, culturing of tissue microexplants as neural tissue spheres (NTS) was established in our laboratory $[19,20]$. In contrast to the classical cellaggregate neurospheres [21, 22], cells in NTS cultures are never dissociated, neither at the time of tissue sampling and culture set up nor at cell passaging.

The domestic pig (Sus scrofa domesticus) is considered a useful nonprimate model in neuroscience because of a better resemblance of the gyrencephalic pig brain to the human brain in the general anatomy, growth, and development compared to the lissencephalic brains of small mammals such as rodents [23-25].

In the present paper, we report for the first time data on efficient long-term propagation of NTS derived from fetal porcine VM.

\section{Experimental Procedures}

2.1. Isolation of Ventral Mesencephalic Tissue. Pig embryos (Danish Landrace $\times$ Yorkshire $\times$ Duroc; Biomedical Laboratory, University of Southern Denmark, DK) of gestational age E28-30 (crown to rump length $=25-27 \mathrm{~mm}$ ) were used. The embryos were removed by hysterectomy from sows (5-9 embryos/preparation; two independent experiments), terminally anesthetized with an intravenous overdose of pentobarbital, and placed in sterile $0.9 \%$ salt solution until removal of the brains. The animal procedures were approved by and conducted in compliance with The Danish Animal Health Care Committee (J. no. 192000/561-272).

Brains were removed from the skull and placed in chilled Gey's balanced salt solution (GIBCO) with $0.5 \%$ D-glucose under sterile conditions. Then, the meninges were gently removed, and the ventral mesencephali isolated by rostral, caudal, lateral, and dorsal cuts (Figure 1).

With the purpose of generating reference material for immunohistochemical staining and characterization of neuronal and glial cell types, VM tissue blocks were fixed in $4 \%$ paraformaldehyde (PFA) in $0.15 \mathrm{M}$ phosphate buffer immediately after isolation.
2.2. Setup and Propagation of VM Neural Tissue Spheres (NTS). Following microscopical inspection, the VM explants were further trimmed for excess tissue and cut into small tissue blocks either by manual division of the tissue blocks into quarters using a scalpel knife or by sectioning the tissue blocks at $350 \mu \mathrm{m}$ using a McIlwain tissue chopper. The resulting tissue blocks were cultured as free-floating NTS in plastic flasks (NUNC) placed in a humidified incubator atmosphere at $36^{\circ} \mathrm{C}$ and $5 \% \mathrm{CO}_{2}$.

For culturing, two different serum-free mitogen-containing media were tested. The first named neurosphere- (NS-) proliferation medium is normally used for our rat stem cell cultures [19] and was composed of a 1:1 mixture of Dulbecco's Modified Eagles Medium (DMEM) and Nut Mix.F12 (Gibco 21331-020) added 0.6\% (w/v) glucose (Sigma), $5 \mathrm{mM}$ Hepes (Gibco), $20 \mathrm{mM} \mathrm{NaHCO}_{3}$ (Sigma), 1\% bovine serum albumin (BSA; Sigma), 1\% Non-Essential Amino Acids (NEAA; Sigma), 1\% N2 supplement (Gibco), $4 \mathrm{mM} \mathrm{L-}$ glutamine (Gibco), 1\% Pen/Strep, $20 \mathrm{ng} / \mathrm{mL}$ human recombinant Epidermal Growth Factor (EGF; R\&D Systems, 236-EG), and $20 \mathrm{ng} / \mathrm{mL}$ human recombinant basic Fibroblast Growth Factor (bFGF; R\&D Systems, 233-FB). The second medium, Human Neural Stem Cell (HNSC-) proliferation medium, is normally used for human neural stem cell cultures [26] and was composed of a $1: 1$ mixture of Dulbeccos Modified Eagles Medium (DMEM) and Nut Mix.F12 with Glutamax (Gibco 31331-028) added 0.6\% $(\mathrm{w} / \mathrm{v})$ glucose (Sigma), $5 \mathrm{mM}$ Hepes (Gibco), 0.5\% (v/v) AlbuMAX-1 (Gibco), 1\% Non-Essential Amino Acids (NEAA; Sigma), 1\% N2 supplement (Gibco), 1\% Pen/Strep (Gibco), $20 \mathrm{ng} / \mathrm{mL}$ EGF, and $20 \mathrm{ng} / \mathrm{mL}$ bFGF. Two-thirds of the medium was replaced twice a week.

When the NTS had reached a diameter of approximately $600-800 \mu \mathrm{m}$, the NTS were passaged (passage $1=\mathrm{P} 1$ ) by manually cutting them under microscopical guidance into quarters using a scalpel knife. Based on the size criteria (see above), the manually cut NTS were first passaged every 68 days (P0-P3), then every 10-14 days (P3-P10) and 15-22 days (P10-P22), while the NTS cut by a tissue chopper first 
were passaged every $20-23$ days ( $\mathrm{P} 0-\mathrm{P} 3)$, then every 29 days (P3-P5), and finally every 39 days (P5-P6).

In the subsequent propagation and differentiation experiments, we did not distinguish between NTS manually cut and NTS processed by a Mcllwain tissue chopper.

The NS-proliferation medium was found not to support long-term proliferation of porcine VM NTS. Therefore, cultures attempted grown in this medium were early on excluded from the study.

2.3. Monitoring of Cell Proliferation in Propagated NTS. For nuclear labelling of proliferating cells in the expanded NTS, $100 \mu \mathrm{M}$ Bromodeoxyuridine (BrdU; Sigma) was added to the mitogen-containing proliferation medium for $24 \mathrm{~h}$ followed by fixation of the cultures in $4 \%$ PFA in $0.15 \mathrm{M}$ phosphate buffer.

2.4. Induced Differentiation of VM NTS after 51-232 Days of Propagation. The factors acidic fibroblast growth factor (aFGF), forskolin, phorbol 12-myristate 13-acetate (TPA), and $\mathrm{N}^{6}, 2^{\prime}$-O-dibutyryladenosine $3^{\prime}: 5^{\prime}$-cyclic monophosphate sodium (db-cAMP) stimulate dopaminergic differentiation in neural rat (our laboratory; unpublished) or human [27] forebrain cultures (in vitro forebrain tyrosine hydroxylase- (TH-) inducing factors), while fibroblast growth factor $8 \mathrm{~b}$ (FGF-8b) and sonic hedgehog (SHH) are essential signalling molecules in the embryonic development of nigral dopaminergic neurons (in vivo midbrain $\mathrm{TH}$ inducing factors) [28].

To induce dopaminergic differentiation of cells propagated as NTS for 51-232 DIV, NTS were plated onto laminin $(20 \mu \mathrm{g} / \mathrm{mL}$; Sigma) and fibronectin-precoated $(20 \mu \mathrm{g} / \mathrm{mL}$; Invitrogen) 6-well plastic plates and the hitherto used proliferation medium replaced by (1) pure mitogen-free HNSC medium, (2) mitogen-free HNSC medium supplemented by $100 \mathrm{ng} / \mathrm{mL}$ human recombinant aFGF (Sigma, F5542), $25 \mu \mathrm{M}$ forskolin (Sigma, F6886), $100 \mathrm{nM}$ TPA (Sigma, P8139), and $100 \mu \mathrm{M}$ db-cAMP (Sigma D0627) (TH-inducing factors), or (3) mitogen-free HNSC medium supplemented by $100 \mathrm{ng} / \mathrm{mL}$ mouse recombinant FGF-8b (R\&D Systems, 423-F8) and $25 \mathrm{ng} / \mathrm{mL}$ mouse recombinant SHH (R\&D Systems, 461-SH). The series of VM NTS were then grown for 10 or 25 days with complete change of media every 4 days.

As a positive control experiment for validation of the biological activity of aFGF, forskolin, TPA, and db-cAMP, a series of pig forebrain NTS cultures, derived from the SVZ of embryos E28-30 days of age (essentially as described by Andersen et al. [19]), were included in the differentiation step parallel to the VM NTS cultures. These SVZ NTS were propagated and selected by the same criteria and methods as described for the VM NTS.

2.5. Histological Processing. Porcine embryonic VM tissue (E28-30) and propagated VM NTS were fixed in 4\% PFA in $0.15 \mathrm{M}$ phosphate buffer at room temperature (RT) for $30 \mathrm{~min}$ and cryoprotected in $0.15 \mathrm{M}$ phosphate buffer containing $20 \%$ sucrose at $4^{\circ} \mathrm{C}$. The tissue was embedded in
Tissue-Tek (AX-LAB a/s), frozen in $\mathrm{CO}_{2}$, and stored at $-20^{\circ} \mathrm{C}$ until cryostat sectioning at $20 \mu \mathrm{m}$. Sections were mounted on gelatinised or Superfrost Plus (BrdU labelled NTS) glass slides and stored at $-20^{\circ} \mathrm{C}$ until immunocytochemical staining. Differentiated NTS $(n=6-18 /$ group/ immunostaining) were fixed in $4 \%$ PFA in $0.15 \mathrm{M}$ phosphate buffer for $20 \mathrm{~min}$, rinsed in $0.15 \mathrm{M}$ phosphate buffer, and kept at $4^{\circ} \mathrm{C}$ in the same buffer until further processing.

2.6. Immunocytochemistry. The three-step Biotin-avidin Horse Radish Peroxidase procedure was used. In brief, all VM cryosections, NTS cryosections, and differentiated NTS were adjusted to RT, rinsed for $3 \times 15 \mathrm{~min}$ in $0.05 \mathrm{M}$ Tris buffered saline (TBS; pH 7.4) containing 1\% Triton X-100 (TBS-T), blocked with $10 \%$ fetal bovine serum (FBS) in $0.05 \mathrm{M}$ TBS for $30 \mathrm{~min}$ at $\mathrm{RT}$, and incubated overnight at $4^{\circ} \mathrm{C}$ with one of the following primary antibodies in $10 \%$ FBS in 0.05 M TBS: anti-Ki67, anti-neuroepithelial stem cell protein (Nestin), anti-Pax6, anti-MASH1, anti- $\beta$ Tubulin III, anti-neuroepithelial associated protein 2 (MAP2), anti-neuronal nuclei (NeuN), anti-tyrosine hydroxylase (TH), anti-Glial Fibrillary Acidic Protein (GFAP), anti-Vimentin, or anti- $2^{\prime}, 3^{\prime}$-cyclic nucleotide $3^{\prime}$-phosphodiesterase (CNPase) (see Supplementary Table 1 in Supplementary material available online at doi:10.1155/2012/761843). The specimens were subsequently transferred to RT, rinsed for $3 \times 15 \mathrm{~min}$ in $0.05 \mathrm{M}$ TBS-T, and incubated for $1 \mathrm{~h}$ at RT with the appropriate secondary antibody, biotinylated sheep anti-mouse (Amersham, RPN1001), or biotinylated donkey anti-rabbit (Amersham, RPN1004) diluted $1: 200$ in $10 \%$ FBS in 0.05 M TBS. Next, specimens were rinsed for $3 \times 15 \mathrm{~min}$ in $0.05 \mathrm{M}$ TBS-T and incubated for $1 \mathrm{~h}$ at RT with horseradish-peroxidase- (HRP) conjugated streptavidin (DAKO, P0397) diluted 1:200 in $10 \%$ FBS in $0.05 \mathrm{M}$ TBS. After further rinsing for $3 \times 15 \mathrm{~min}$ in $0.05 \mathrm{M}$ TBS, the HRP was visualized by exposure to $0.05 \%$ diaminobenzidine (DAB) and $0.033 \% \mathrm{H}_{2} \mathrm{O}_{2}$ dissolved in $0.05 \mathrm{M}$ TBS. Samples were then rinsed $3 \times 15 \mathrm{~min}$ in $0.05 \mathrm{M}$ TBS, and VM and NTS cryosections were dehydrated in ethanol $(70,96,99 \%, 2 \times 5$ min each), cleared in xylene ( 3 $\times 5 \mathrm{~min})$, and cover-slipped in DePex (BDH). Differentiated NTS were cover-slipped in Aquatex (VWR) immediately after the final rinse.

For BrdU immunocytochemistry, NTS cryosections were adjusted to RT, rinsed for $3 \times 15 \mathrm{~min}$ in $2 \times$ Saline Sodium Citrate (SSC; Merck), incubated for $2 \mathrm{~h}$ in $2 \times$ SSC $/ 49 \%$ formamide (Bie \& Berntsen) at $60^{\circ} \mathrm{C}$, rinsed in $2 \times$ SSC for $2 \times 5 \mathrm{~min}$ at $60^{\circ} \mathrm{C}$, incubated in $2 \mathrm{~N} \mathrm{HCL} / 0.05 \mathrm{M}$ TBS for $30 \mathrm{~min}$ at $37^{\circ} \mathrm{C}$, and rinsed for $10 \mathrm{~min}$ in $0.1 \mathrm{M}$ Borate buffer (Merck, pH 8.5) followed by $15 \mathrm{~min}$ in $0.05 \mathrm{M}$ TBS. Thereafter the sections were subjected to the standard threestep Biotin-avidin Horse Radish Peroxidase procedure as described above, using a mouse anti-BrdU antibody (DAKO; M0744) diluted 1:200 (Supplementary Table 1).

For control of specificity, the primary antibody was either omitted or substituted in equivalent concentrations with either isotype-specific mouse $\mathrm{IgG}_{1}$ (DAKO, X0931), mouse $\mathrm{IgG}_{2 \mathrm{a}}$ (DAKO, X0943), or rabbit IgG fraction (DAKO, X0903). A Leica DC camera fitted to a Zeiss Axiophot 


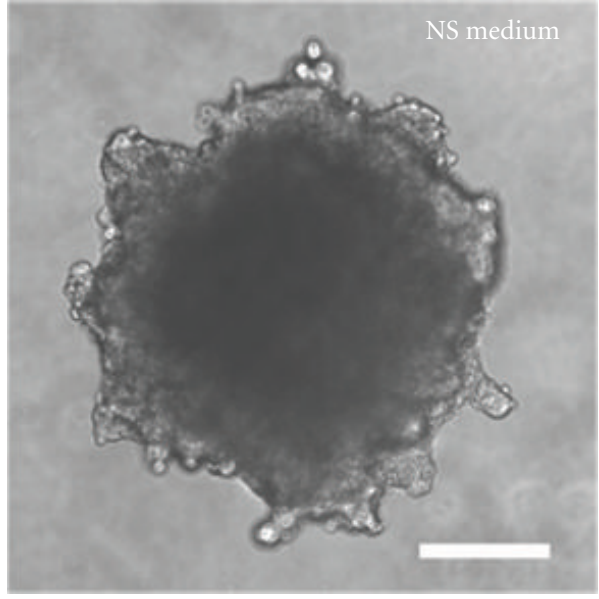

(a)

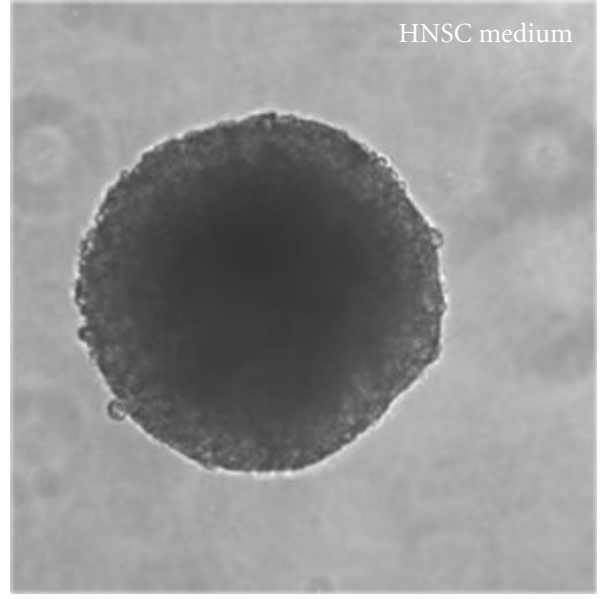

(b)

FIGURE 2: Long-term propagated porcine ventral mesencephalic (VM) neural tissue spheres (NTS). The NTS were propagated in either (a) neurosphere- (NS-) proliferation medium or (b) human neural stem cell- (HNSC-) proliferation medium. Scale bar: $200 \mu \mathrm{m}$.

microscope was used for acquiring photomicrographs for documentation.

2.7. Cell Counting and Statistical Analysis. Quantification of Ki67-positive and BrdU-positive cells in NTS was performed on $20 \mu \mathrm{m}$ cryostat sections. Images were obtained at $100 \mathrm{x}$ magnification. A grid, dividing the NTS into quarters, was overlaid, and Ki67-positive or BrdU-positive cells were counted in one square (representing $25 \%$ of the section area) using the cell counting tool of FluoroView 2.1b (Olympus). The area of each NTS section was measured by delineating the NTS using CAST Grid system software (Olympus). Data are presented as average number of cells per $\mathrm{mm}^{2} \pm$ SEM.

Statistical comparison was performed by means of commercially available software (InStat, GraphPad software). Densities of Ki67-positive or BrdU-positive cells were compared by the parametric one-way analysis of variance (ANOVA) followed by Student-Newman-Keuls multiple comparison test. Differences were considered statistically significant at $P<0.05$ indicated by ${ }^{*}, P<0.01$ indicated by $* *$, and $P<0.001$ indicated by $* * *$.

\section{Results}

3.1. Preparation and Propagation of Neural Tissue Spheres (NTS) Derived from Embryonic Porcine Ventral Mesencephalic (VM) Tissue. Two different tissue preparations for setup of NTS from embryonic porcine VM were tested, namely, microscopic guided manual division of the primary isolated VM tissue block into quarters or sectioning at $350 \mu \mathrm{m}$ by a McIlwain tissue chopper.

Whereas $85-90 \%$ of the manually cut VM tissue blocks rounded up and formed spherical structures within 24 hours in culture, the tissue samples sectioned by tissue chopper had a lower survival rate (40-50\%) immediately after establishment and a longer and more protracted recovery period. After 8 days in vitro (8 DIV), a large fraction of sectioned VM tissue samples had not rounded up or displayed cavities in the spherical structures. Nonspherical tissue was discarded, and only spherical tissue fragments were included in the study. The sectioning at $350 \mu \mathrm{m}$ also affected the overall growth rate as documented by prolonged growth periods to reach a passaging diameter of $600-800 \mu \mathrm{M}$, as compared to the manually cut NTS. The sectioning did not, however, affect the ability for long-term propagation or the composition of cell types in propagated and differentiated NTS (data not shown). For that reason, we did not-unless specifically mentioned-distinguish between manually or tissue chopper sectioned NTS in the following differentiation experiments.

Two different serum-free and mitogen-containing proliferation media, originally developed for culturing of neural stem and progenitor cells, were compared for their ability to stimulate the growth and hence propagation of our porcine NTS. NS-proliferation medium and HNSC-proliferation medium are normally used for murine and human cultures, respectively. The NS-proliferation medium failed to support long-term proliferation of the porcine VM NTS. After 33 days, the proliferative capacity of NTS cultured in NSproliferation medium was clearly reduced compared to that of NTS cultured in HNSC-proliferation medium. Also the NTS cultured in NS-proliferation medium were unable to form proper spherical structures (Figure 2(a)). As a consequence, use of the NS-proliferation medium was stopped and the cultures excluded from the differentiation study.

In contrast, NTS propagated in HNSC-proliferation medium were viable with display of significant proliferative capacity after propagation for more than 237 days (Figure 2(b)).

A significant mitotic activity, visualized by Ki67 expression and BrdU incorporation, was observed in both young $(\mathrm{P} 6=63 \mathrm{DIV})$ and long-term propagated cultures $(\mathrm{P} 18=$ 237 DIV) (Figure 3). The Ki67 expressing cells predominantly showed a peripheral distribution with the cells 
63 DIV (P6)

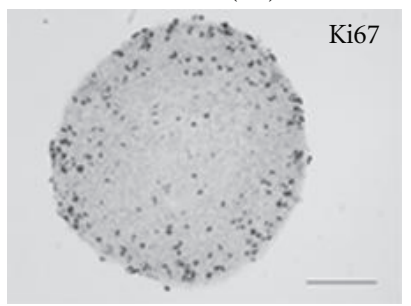

(a)

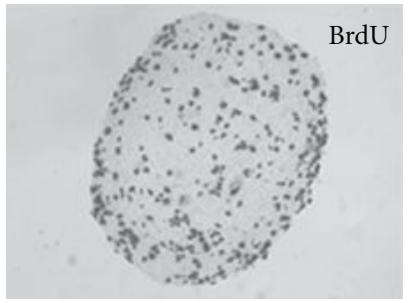

(d)

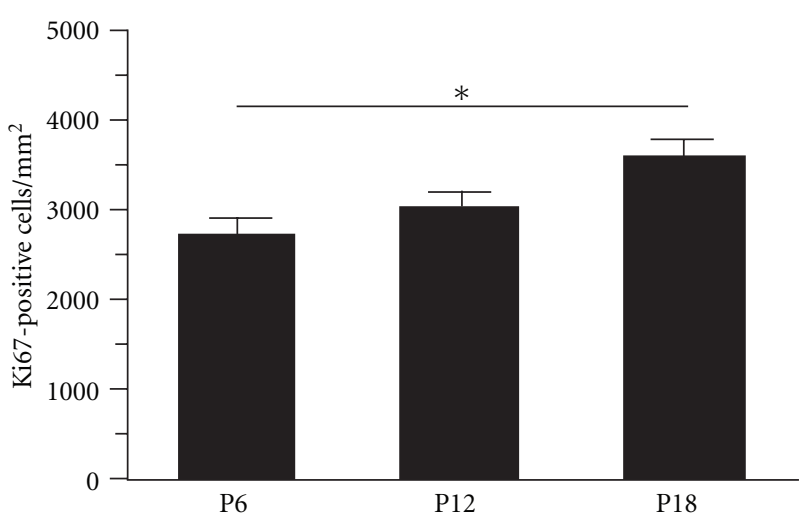

(g)
141 DIV (P12)

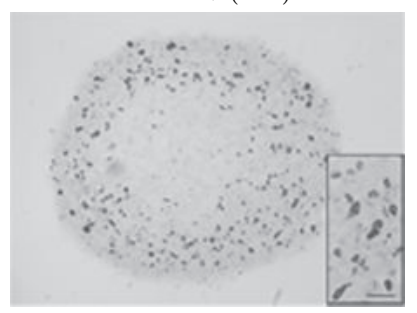

(b)

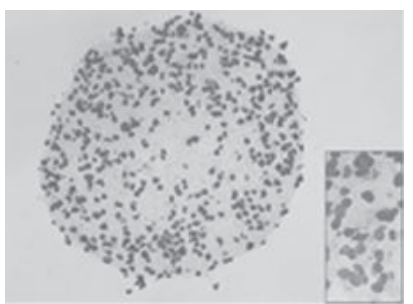

(e)

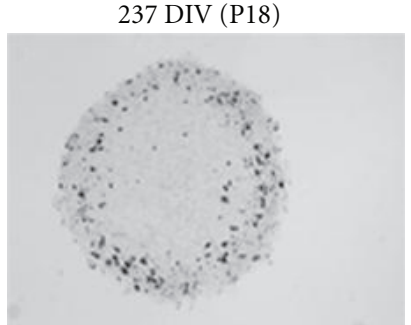

(c)

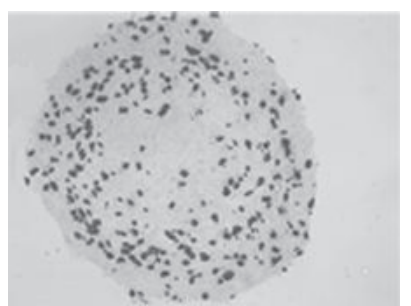

(f)

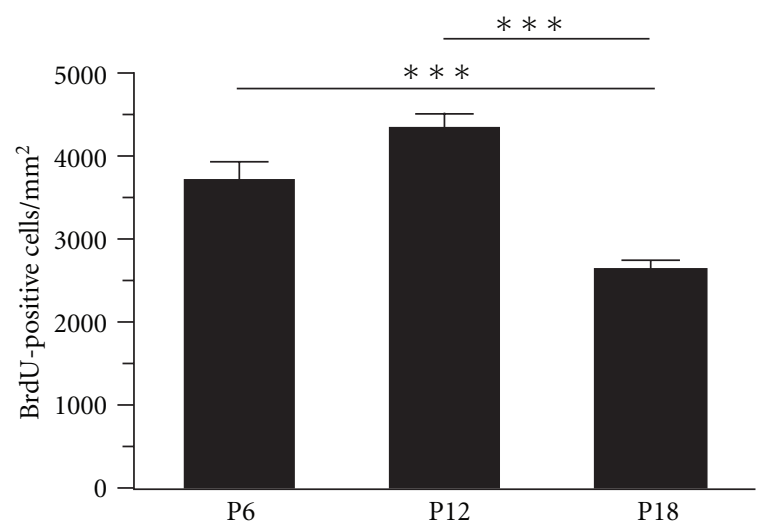

(h)

FIGURE 3: Proliferation in long-term propagated porcine ventral mesencephalic (VM) neural tissue spheres (NTS) visualized by Ki67 and BrdU immunostaining of histological sections. Photomicrographs of NTS showing expression of Ki67 at (a) 63 days in vitro (DIV) (passage (P) 6), (b) 141 DIV (P12), (c) 237 DIV (P18) and BrdU labelling at (d) 63 DIV, (e) 141 DIV, and (f) 237 DIV. Scale bars: $100 \mu \mathrm{m}$ (overview) and $20 \mu \mathrm{m}$ (insert). Quantification of Ki67 (g) and BrdU (h) expressing cells showed significantly more Ki67-positive cells at P18 as compared to P6, whereas there were significantly more BrdU-positive cells at P6 and P12 as compared to P18. Data are expressed as mean \pm SEM $\left(n=15-19 ;{ }^{*} P<0.05,{ }^{* * *} P<0.001\right)$.

forming an outer rim in the NTS (Figures $3(a)-3(c)$ ). The BrdU-positive cells were more numerous and were evenly distributed in the NTS, yet maintaining a slightly higher cell density in the peripheral zones (Figures 3(d)-3(f)). The distribution pattern of BrdU labelled cells suggests some postmitotic/postlabelling migration from the periphery towards the center of the NTS. Quantification of Ki67positive cells revealed a slight increase in cell densities at higher passages, which was significant at P18 as compared to P6 (Figure 3(g)). Quantification of BrdU-positive cells showed that there were significantly more BrdU-positive cells at P6 and P12 as compared to P18 (Figure 3(h)).

\subsection{Characterization of Noncultured Foetal Porcine VM} Tissue. To investigate the presence and the composition of neural cell types in situ before culturing, freshly isolated (noncultured) embryonic (E28-E30) porcine VM tissue was immunostained for several proliferation and cell-type markers (Figure 4).

In the primary VM tissue, the cell proliferation marker Ki67 was sparsely present with the highest density of cells in the periphery (Figure 4(b)). Pax6, a transcription factor present in proneural cell types, was expressed in round cell nuclei located ventrolaterally to the developing substantia nigra pars compacta and ventral tegmental area (Figure $4(\mathrm{c})$ ). The transcription factor MASH1 was detected only sparsely and found in oval/fusiform cell nuclei distributed in the VM with a tendency of more frequent occurrence lateral to the developing substantia nigra pars compacta and ventral tegmental area (Figure 4(d)).

Cellular expression of the cytoskeletal proteins nestin and vimentin, commonly used for identification of neuroepithelial precursor cells, and GFAP, which is present in both 


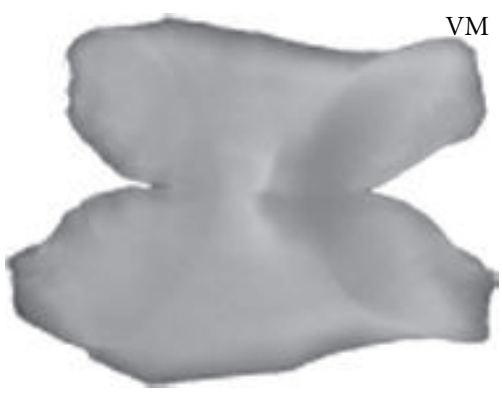

(a)

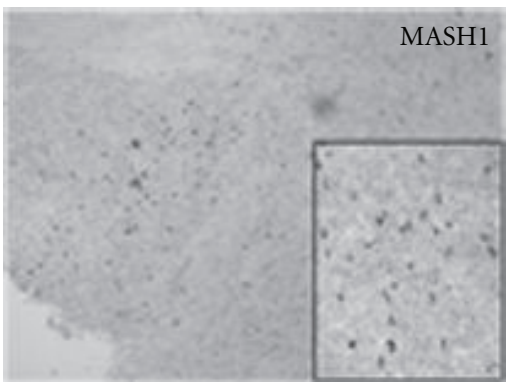

(d)

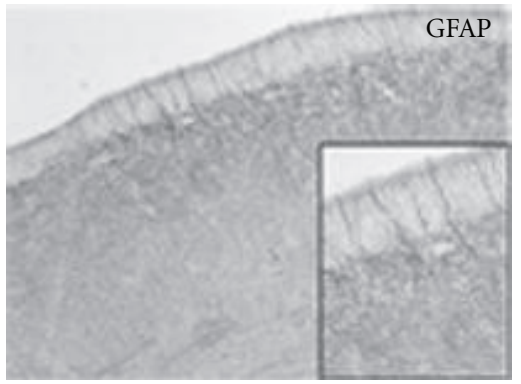

(g)

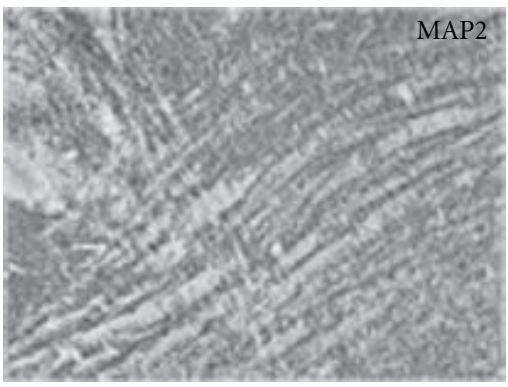

(j)

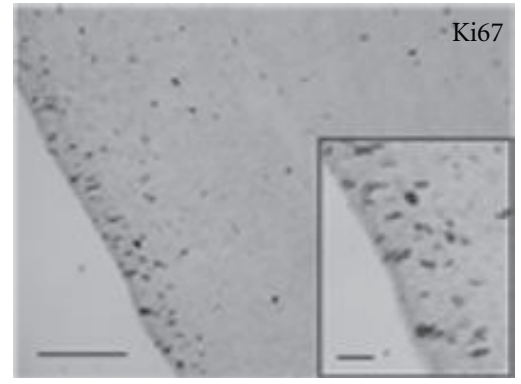

(b)

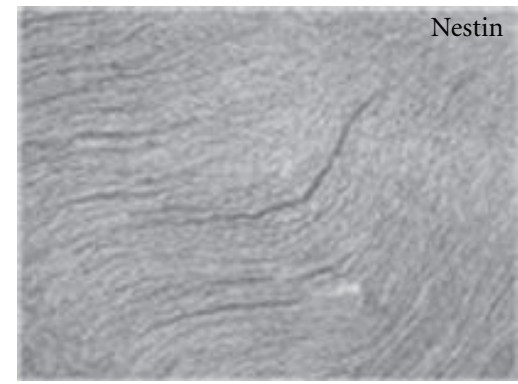

(e)

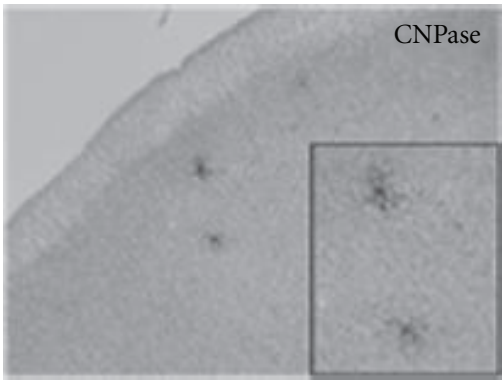

(h)

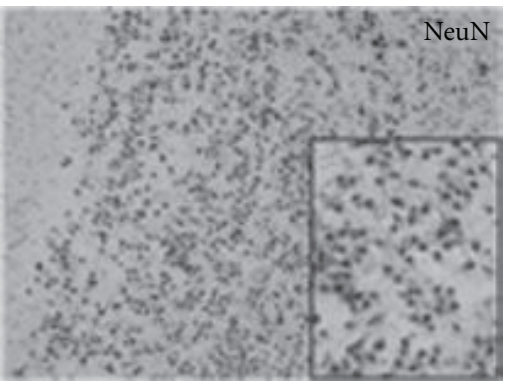

(k)

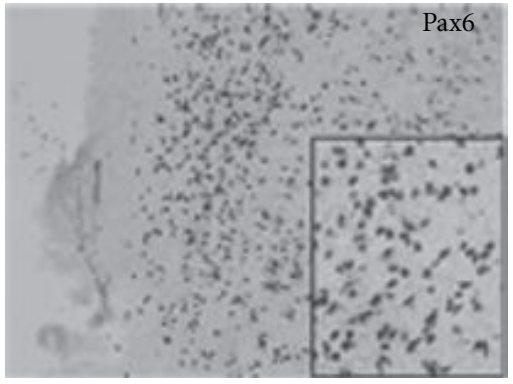

(c)

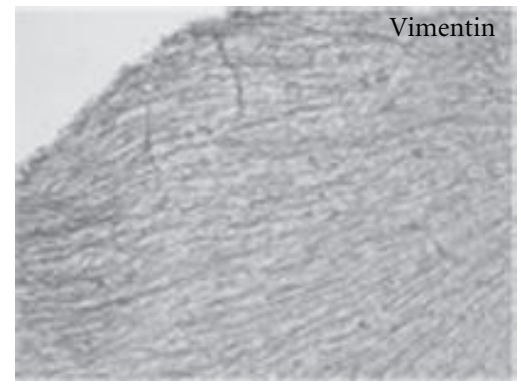

(f)

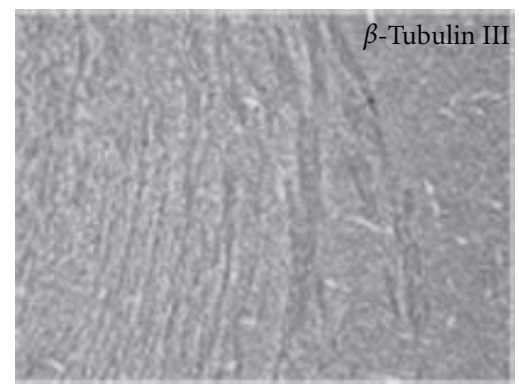

(i)

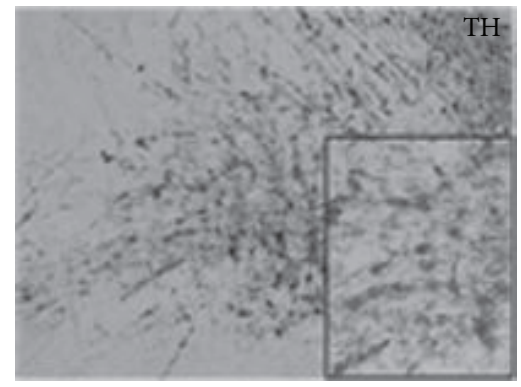

(1)

FIGURE 4: Expression of stem cell markers and markers of glial and neuronal cells in primary (noncultured) porcine ventral mesencephalon (VM) obtained at embryonic day 28-30. Photomicrographs showing an intact VM (a), and immunoexpression of the proliferation marker Ki67 (b), the proneural markers Pax6 (c) and MASH1 (d), the neural stem cell marker nestin (e), the glial markers vimentin (f) and GFAP $(\mathrm{g})$, the oligodendrocyte marker CNPase $(\mathrm{h})$, the neuronal markers $\beta$ Tubulin III (i), MAP2 (j) and NeuN (k), and the dopaminergic marker TH (1). Scale bars: $100 \mu \mathrm{m}$ (overview) and $20 \mu \mathrm{m}$ (insert).

mature astrocytes and some neural stem/progenitor cells, was found widespread in the VM tissue (Figures $4(\mathrm{e})-4(\mathrm{~g})$ ).

The oligodendrocyte marker CNPase labelled very few cells in the embryonic porcine VM. The cells present had a "bushy" appearance characteristic of immature oligodendroglia (Figure 4(h)). $\beta$ Tubulin III, which is expressed in immature neurons and neuroepithelial cells committed to neuronal fate, was expressed in a large number of cells in the embryonic porcine VM (Figure 4(i)). Cells, positive to the cytoskeletal protein MAP2ab and the nuclear protein NeuN (Figures 4(j)$4(\mathrm{k})$ ), both markers specific to neurons at a certain stage 


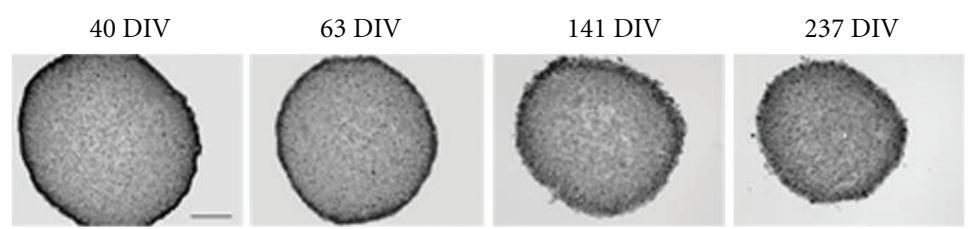

(a)
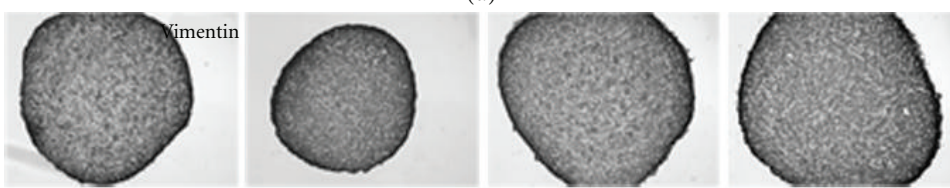

(b)
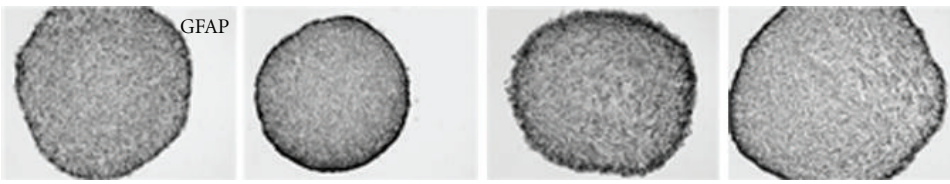

(c)
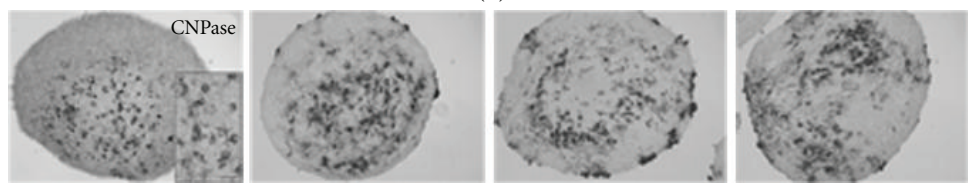

(d)
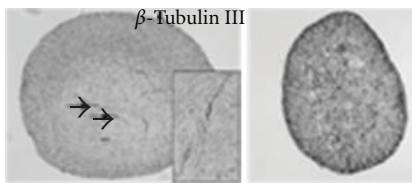

20 DIV

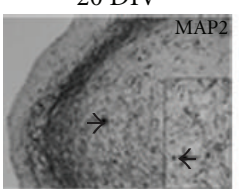

(f)

41 DIV

) (e)

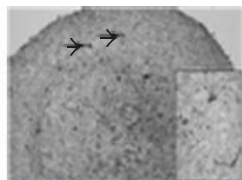

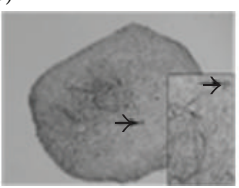

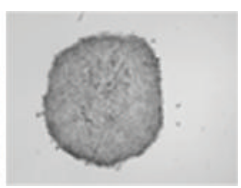

20 DIV
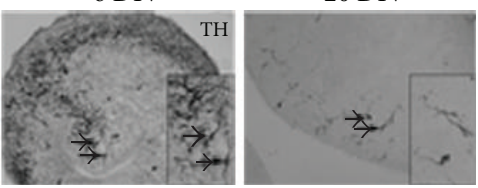

(g)

FIGURE 5: Neural stem cell, glial, and neuronal markers in long-term propagated embryonic porcine ventral mesencephalic, neural tissuespheres (NTS), stained after 40, 63, 141, and 237 days in vitro (DIV). Photomicrographs showing immunoexpression of nestin (a), vimentin (b), GFAP (c), CNPase (d), and $\beta$ Tubulin III (e) in NTS. The neuronal marker MAP2 and the dopaminergic marker TH were not expressed in the long-term propagated NTS, but younger NTS cultures showed MAP2 expression (f) in NTS after 20 and 41 DIV and TH expression (g) after 6 and 21 DIV. Arrows mark neuronal cell soma magnified in inserts. DIV = days in vitro. Scale bars $=100 \mu \mathrm{m}($ overview) and $20 \mu \mathrm{m}$ (insert).

of development or fully mature neurons, were distributed throughout the VM with display of a characteristic neuronal morphology in the MAP2ab staining. TH, which is the rate-limiting enzyme in dopamine synthesis, was expressed in cells displaying a neuronal morphology localized in the developing substantia nigra pars compacta and ventral tegmental area of the VM (Figure 4(1)).

\subsection{Characterization of Porcine VM NTS after Long-Term} Propagation. To address temporal changes of cell-type composition and distribution in the long-term cultured NTS, cells were fixed at days 40,63, 141, and 237 corresponding to passages $4,6,12$, and 18 , respectively, and immunostained for the same proneural, glial, and neuronal markers as described above for the noncultured VM tissue from embryonic porcine brain.

Whereas Pax6 and MASH1 expressing cells were observed in the noncultured VM (Figures 4(c)-4(d)), no Pax6- and MASH1-positive cells were identified at any stage in the propagated NTS. In contrast, cells positive for nestin, vimentin, and GFAP were present at high density throughout the NTS at all examined stages of propagation (Figures 5(a)5(c)).

CNPase-positive cells were identified in clusters in the core of the NTS (Figure 5(d)). The highest density of CNPase-positive cells was observed in the oldest cultures (Figure 5(d); $237 \mathrm{DIV}$ ), but the distribution and number of CNPase-positive cells did vary considerably between the individual NTS. 
Few $\beta$ Tubulin III-positive cells were seen in the NTS cultures (Figure $5(\mathrm{e})$ ). In cultures grown for 40 days, the $\beta$ Tubulin III-positive cells showed a well-preserved neuronal morphology characterized by a distinct soma with dendritic and axonal ramifications (Figure 5(e); 40 DIV). In older cultures, the morphology was less defined, and primarily $\beta$ Tubulin III-positive cell processes could be identified (Figure 5(e); 141 and 237 DIV).

No NeuN-positive, MAP2ab-positive, or TH-positive cells were observed in the long-term propagated NTS at 63-237 DIV. In contrast to this, both MAP2ab-positive (Figure 5(f)) and TH-positive (Figure 5(g)) cells were present in the newly established NTS (6-41 DIV), while NeuN-positive cells were not identified in newly established NTS either. The data suggest that the fully differentiated neuronal cells in the NTS were eliminated in the NTS with increased propagation time. It could be suspected that this was caused by the use of HNSC-proliferation medium, which "favours" undifferentiated cells, and the passaging technique, which may disrupt the neuronal cell processes and connections.

3.4. Differentiation of VM Spheres. Differentiation of the NTS was induced by change to HNSC medium without mitogens and addition of factors known to induce dopaminergic differentiation either in vitro in rat (our laboratory; unpublished) or human forebrain cultures [27] or in vivo during the normal development of nigral dopaminergic neurons $[28,29]$. VM NTS cultures aged between 51 and 232 days were differentiated for 10 or 25 days after plating onto laminin/fibronectin coated plastic plates (Table 1).

Following plating, cells migrated away from the NTS, forming a monolayer of cells arranged as a halo around a central cell mass.

$\beta$ Tubulin type III and TH were used as markers for immature neurons and dopaminergic neurons, respectively. None of the protocols did stimulate dopaminergic differentiation of the VM NTS, as indicated by the absence of THpositive cells. Instead intense $\beta$ Tubulin type III immunoreactivity was observed in the central cell mass of the plated NTS (Figure 6(a)). Most of the cells in the differentiated VM NTS, however, expressed the astroglial marker GFAP and exhibited characteristic astroglial morphology (Figure 6(a)).

3.5. Differentiation of Porcine Subventricular Zone (SVZ) Spheres. Culturing of porcine NTS derived from the SVZ of 28-30-day-old embryos, in either mitogen-free medium or mitogen-free medium supplemented by aFGF, forskolin, TPA, and db-cAMP stimulated $\beta$ Tubulin type III and TH expression, verified a differentiating action of these factors on porcine cultures (Figures 6(b)-6(c)). $\beta$ Tubulin type IIIpositive cells displaying characteristic neuronal morphology were located both in the halo of migrated cells and in the central cell mass of the differentiated SVZ NTS (Figures 6(b)6(c)). TH-positive cells were also identified in the differentiated SVZ NTS (Figures 6(b)-6(c)). The TH expressing cells in the mitogen-free cultures were fewer and appeared more mature by having more and longer processes (Figure 6(b))
TABLE 1: Differentiation of long-term propagated neural tissuespheres (NTS) derived from the embryonic porcine ventral mesencephalon (VM).

\begin{tabular}{lclc}
\hline $\begin{array}{l}\text { Age } \\
\text { (DIV) }\end{array}$ & $\begin{array}{c}\text { Passage } \\
\text { (P) }\end{array}$ & Protocol(s) & $\begin{array}{c}\text { Duration } \\
\text { (days) }\end{array}$ \\
\hline 51 & P2 & $\begin{array}{l}\text { (1) Mitogen-free } \\
\text { (2) a-FGF, forskolin, TPA, db-cAMP }\end{array}$ & 25 \\
170 & P14 & $\begin{array}{l}\text { (1) Mitogen-free } \\
\text { (2) a-FGF, forskolin, TPA, db-cAMP }\end{array}$ & 10 \\
232 & P18 & $\begin{array}{l}\text { (1) Mitogen-free } \\
\text { (2) FGF8 + sonic hedgehog }\end{array}$ & 10 \\
\hline
\end{tabular}

than the TH-positive cells in the cultures exposed to the THinducing factors (Figure 6(c)).

\section{Discussion}

In vitro expansion of ventral mesencephalic (VM) precursor cells constitute an interesting alternative to primary fetal VM tissue for intrastriatal transplantation in Parkinson's disease (PD) $[8,30]$. Facilitated dopaminergic differentiation of such cells has, however, proven difficult, calling for improved expansion and differentiation protocols.

The domestic pig (Sus scrofa domesticus) is an excellent nonprimate large animal model in neuroscience due to the many physiological and biological similarities between human and porcine biology $[31,32]$. The pig brain is large enough to provide excellent visualisation, for example, in positron emission tomography and magnetic resonance imaging. Porcine somatic cell nuclear transfer (SCNT) technologies have made the production of transgenic pig models possible [33-35]. Recently, a porcine model for Alzheimer's disease has been developed using "the handmade cloning (HMC) method," an alternative technique for SCNT, which simplifies the cloning procedure and increases the efficiency [36, 37]. Other porcine models of human brain disorders, like, for instance, the MPTP-induced model of PD, have also been developed [38].

Due to the limited availability of human fetal VM tissue, the pig has been suggested as a nonprimate donor of VM tissue containing dopaminergic neurons and porcine-tohuman xenotransplantation of VM tissue has been conducted in a clinical trial [39]. Although immunological rejection processes are induced in human recipient brains by the discordant porcine xenograft, this can be reduced or inhibited by immunosuppression [40]. A very promising application of the new transgenic technology could be the development of genetically engineered pigs for xenotransplantation minimizing graft rejection.

In the present study, porcine VM tissue derived as small tissue pieces from 28-30-day-old embryos was long-term propagated and differentiated as so-called neural tissuespheres (NTS) [19]. In the NTS system, an in vivo-like, organotypic microenvironment is intended to be preserved by avoiding mechanical and enzymatic dissociation thereby 

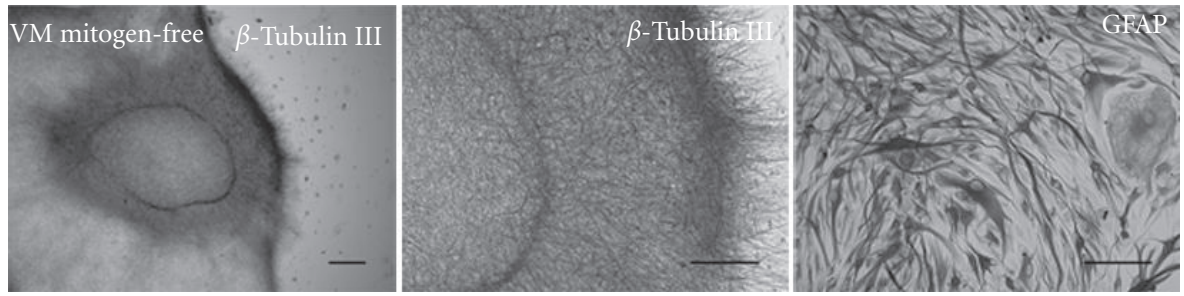

(a)
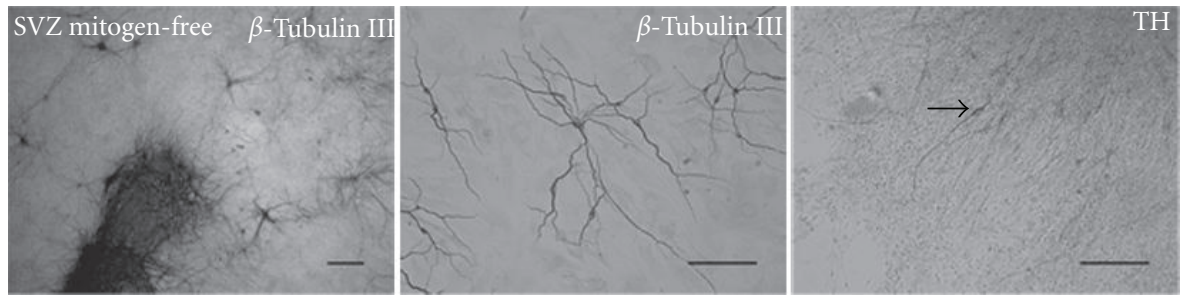

(b)
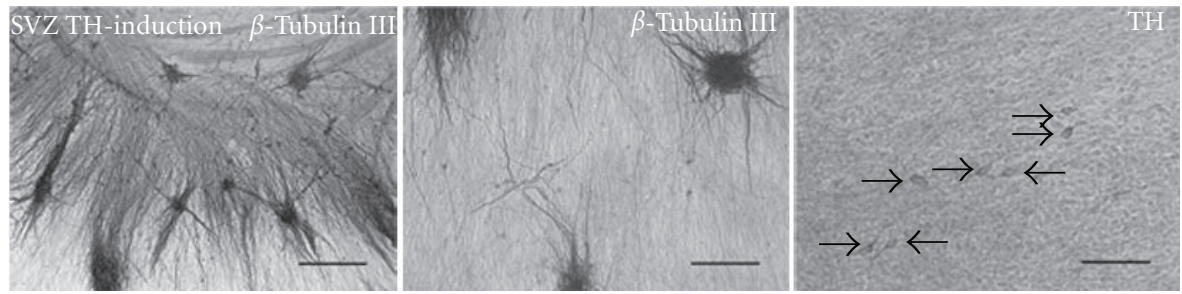

(c)

FIGURE 6: Differentiation of long-term propagated embryonic porcine neural tissue spheres (NTS). Differentiation of VM NTS (51 and 170 days of age) induced by mitogen withdrawal did after 25 days induce a high number of $\beta$ Tubulin III positive cells in the central core of the differentiated NTS (a), but no TH-positive cells were identified. Instead, the differentiated cells primarily expressed the astroglial marker GFAP and displayed a characteristic astroglial morphology. To verify the differentiation potential of the protocols used, 51-day-old NTS cultures derived from the embryonic porcine subventricular zone (SVZ) were included in the differentiation study as a positive control. Differentiation of SVZ NTS for 25 days by mitogen withdrawal (b) or by addition of the TH-inducing factors a-FGF, forskolin, TPA, and dbcAMP (c), known to stimulate TH expression in mammalian forebrain cultures, both resulted in $\beta$ Tubulin III- and TH-positive cells. The $\beta$ Tubulin III-positive cells had a characteristic neuronal morphology and were located in clusters/clones in the zone of migrating cells and in the central core of the differentiated SVZ NTS. The TH-positive cells were more numerous and appeared more morphologically immature by having shorter processes (c) compared to the cultures differentiated under mitogen-free conditions (b). Arrows mark soma of TH-positive cells. Scale bars $=200 \mu \mathrm{m}$ and $100 \mu \mathrm{m}$ in microphotographs of $\beta$ Tubulin III expression at low and high magnification, respectively. $100 \mu \mathrm{m}$ in microphotographs of GFAP and TH expression.

maintaining cell integrity, intercellular contact, and cell-cell interaction.

Twenty-eight-day-old embryonic porcine VM shows a certain resemblance to the human VM 6-6.5 weeks postcoitus [41]. TH-positive cells have been identified in the developing human midbrain as early as 3.5 weeks of gestational age, and human fetal VM tissue 6.5-9 weeks of age is considered optimal for transplantation in $\operatorname{PD}[42,43]$. At 28 days of age, the embryonic porcine VM contains $\mathrm{TH}$ differentiated, dopamine-synthesizing, but otherwise morphologically immature cells with undifferentiated, short processes, capable of surviving and developing in vitro and optimal for xenotransplantation in PD patients [41].

Isolated embryonic porcine VM tissue, manually cut into small blocks rounded up and formed NTS within 24 hours, could be maintained and propagated in culture for more than
230 days, using a proliferation medium for human neural stem cells containing the mitogens EGF and bFGF [26]. These results are in good agreement with other studies in our laboratory of long-term culturing of rat and human SVZ and VM as NTS $[19,20,44]$. Here we observed that media used for propagation murine neural stem cells were unable to support long-term propagation of porcine VM NTS.

The NTS method is a modification of the neurosphere techniques originally developed by Reynolds and Weiss [22] and Svendsen et al. [21]. In the neurosphere culture method, passaging by tissue chopping is used successfully for largescale expansion of nontransformed neural precursor cells isolated from the human cortex. However, our results showed impaired NTS formation when applying a McIlwain tissue chopper instead of manually cutting the porcine VM tissue during passaging. The NTS failed to round up properly. Our 
observations thus indicate a higher sensitivity to mechanical stress of porcine brain tissue compared to human tissue and/or midbrain tissue versus forebrain tissue.

4.1. Cellular Content of Propagated NTS. Using cell proliferation and cell-type markers, the proliferative activity and cell-type composition of NTS were evaluated at defined propagation stages of porcine VM NTS.

In contrast to a sparse occurrence of proliferating cells in the primary VM tissue identified by Ki67, a significant proliferative activity was visualized by Ki67 immunostaining and BrdU labelling in both young $($ P6 $=63 \mathrm{DIV})$ and old VM NTS cultures $($ P18 = 237 DIV $)$. The occurrence of the dividing Ki67-positive cells were primarily confined to the peripheral part of the NTS, while BrdU-positive nuclei were more evenly distributed in the NTS, even that the highest cell density was found peripherally.

Ki67-expression reflects mitotic activity at the time of fixation, while BrdU incorporation covers a wider time span corresponding to the 24-hour exposure period. Several BrdU-positive cells are therefore expected to be postmitotic at the time of fixation. In the superficial parts of the NTS, the nutritional condition and oxygen level might be supportive for cell proliferation, while the BrdU-positive cells located in a more central part of the NTS are likely to be postmitotic cells that have migrated into the deeper parts of the NTS but may also represent cells undergoing DNA repair [45].

Previous data from our laboratory have shown a change from a peripheral distribution of Ki67- and BrdU-positive nuclei in young ( $\mathrm{P} 2=35 \mathrm{DIV})$ NTS, derived from foetal rat VM to a more evenly distribution in older NTS [20]. The rat VM NTS were propagated in media containing leukemia inhibitory factor (LIF) and bFGF, instead of EGF and bFGF, and this might explain the discrepancy between the spatial distribution of proliferative cells in long-term propagated porcine and rat VM NTS. Differences in culture treatment might also have influenced the outcome.

The proneural transcription factors Pax6 and MASH1 are essential in both fetal and adult/postnatal neurogenesis in the mammalian brain. Pax6 and MASH1 are expressed by neural stem/progenitor cells in the two adult brain neurogenic zones, that is, the SVZ of the lateral ventricle and the subgranular zone of the hippocampal dentate gyrus [46-48]. The factors seem to function in the early steps to balance proliferation and differentiation of neural stem cells.

In this study, the proneural markers Pax6 and MASH1 were identified in the porcine primary VM tissue corresponding to start of culturing, but were not found in the cultured VM NTS at any stage of propagation. Using RTPCR analyses, Kukekov et al. [49] have previously shown the presence of Pax6 RNA transcripts in neurosphere cultures derived from the periventricular subependymal zone and the hippocampus of the adult human brain (age 24-57 years).

Expression of structural proteins like nestin (neuroepithelial stem cell protein) and vimentin, which both are intermediate filament proteins, is used for positive identification of neuroepithelial stem cells $[50,51]$. Recently, another cytoskeletal protein, GFAP (glial fibrillary acid protein), formerly believed to be expressed exclusively in differentiated glial cells, has been identified in neural stem/progenitor cells in the adult mammalian SVZ and hippocampus [52, 53]. Nestin, vimentin, and GFAP expression have been found to be expressed in neural progenitor cells isolated from the postmortem human cortex [54].

In our NTS system, nestin, vimentin, and GFAP proteins were widely expressed in both the primary VM tissue as well as in the NTS cultures during the entire long-term propagation period. Nestin, vimentin, and GFAP-positive cells were evenly distributed in the NTS and no decrease in the intensity of the immunostaining was seen with increasing age of the cultures. Mature astrocytes also express GFAP and the pool of GFAP-positive cells therefore must include fully differentiated glia, at least in the younger NTS.

During the long-term propagation period (237 DIV), the porcine VM NTS displayed an increase in number of CNPase-positive cells with structural resemblance to oligodendrocytes appearing in clusters primarily in the central core of the cultures. The cells confirm the presence of a core microenvironment sufficient in nutrition and oxygen for maintaining cell metabolism.

Only few CNPase expressing cells were identified in the primary VM tissue before culturing. The temporal increase in the number of oligodendrocytes in the cultured NTS probably reflects an intrinsic histogenetical programming of the VM tissue, which persists in the in vitro culture conditions. It is well known that oligodendroglia appear later than neurons in the histogenesis of the nervous system and continues to develop postnatally [55].

Besides neural precursor cells and differentiated glial cells, the acutely isolated E27-30-day-old porcine VM tissue contained mature and immature neurons verified by the expression of the MAP2 (mature), TH (dopaminergic), and $\beta$ Tubulin III (immature) neuronal markers. Whereas immature neuronal cells expressing $\beta$ Tubulin III could be identified in both young and old NTS, the mature neurons died off within the first passages of the NTS (MAP2 = $42 \mathrm{DIV} ; \mathrm{TH}=21 \mathrm{DIV}$ ) in the presence of a serum-free, bFGF, and EGF containing proliferation medium, leaving only the stem/progenitor cells to proliferate. The sustained expression of $\beta$ Tubulin III might be the result of a spontaneous neuronal differentiation of precursor cells within the propagated NTS previously demonstrated in the classical neurosphere assay [56].

4.2. Induced Differentiation of VM NTS. Studies have shown that the neuronal outcome of differentiation of intact neurospheres is higher compared to the outcome from dissociated cultures and that differentiation at high cell densities yields more neurons compared to differentiation at low densities, demonstrating the importance of intercellular contact during neuronal development $[18,57]$.

In the present study, porcine VM NTS, aged 51-232 DIV, were plated onto laminin-coated plastic plates and left to differentiate for 10 or 25 days in either mitogen-free medium or mitogen-free medium supplemented by aFGF, forskolin, TPA, and db-cAMP or FGF-8b and SHH. 
Whereas removal of mitogens from the culture medium induces a noncell-type-specific differentiation, addition of the factors aFGF, forskolin, TPA, and db-cAMP induces tyrosine hydroxylase $(\mathrm{TH})$ expression in rat forebrain cultures and cultures of the NT2/hNT cell line, derived from human teratocarcinoma cells [29]. The factors seem to stimulate TH expression by activating the protein kinase A (PKA) and protein kinase $\mathrm{C}$ ( $\mathrm{PKC}$ ) signalling pathways [29].

Shh and FGF-8b are essential inducers of dopaminergic differentiation at specific induction sites in the midbrain and forebrain in rat embryos [28]. Results from our laboratory have also demonstrated a mitogen effect of FGF-8b on midbrain dopaminergic precursor cells from rat embryos $[9,58]$.

None of the protocols tested in this study stimulated dopaminergic differentiation/TH expression in the porcine VM NTS, but did induce $\beta$ Tubulin type III expression. Most of the cells in the differentiated VM NTS expressed the astroglial marker GFAP and exhibited characteristic astroglial morphology.

When porcine subventricular zone (SVZ) NTS derived from E28-30-day-old embryos were grown in either mitogen-free medium or mitogen-free medium containing aFGF, forskolin, TPA, and db-cAMP, the expression of $\beta$ Tubulin type III and TH was enhanced verifying the relevance of applying these protocols to porcine cultures. Speculatively, it may be suggested that aFGF, forskolin, TPA, and $\mathrm{db}$-cAMP are forebrain-specific inducers of dopaminergic differentiation, which, however, are unable to induce dopaminergic differentiation of midbrain-derived precursor cells.

FGF-8b and SHH are key factors in the development of midbrain dopaminergic cells in vivo, but might be inadequate for induction of the dopaminergic phenotype in vitro. For instance, cotreatment with FGF-8b and SHH only has a minor TH-inductive effect (less than 5\%) on mouse embryonic striatal precursor cells and the human stem cell line NT2/hNT in vitro [59]. Of course, the discrepancies between the in vivo and in vitro data could reflect differences between the origin and the developmental stage of the cell types studied, but an alternative and plausible interpretation might also be that one or more additional mediators are essential for induction and specification of the midbrain dopaminergic neuron in vivo. One such molecule could be transforming growth factor- $\beta$ (TGF- $\beta$ ), which has been shown to be essential for the induction and maintenance of midbrain dopaminergic neurons both in vitro and in vivo in chicken and rat models [60].

Even without a direct dopaminergic potential, the NTS might still be relevant for transplantation in PD. A recent study by Moses et al. [61] has shown that long-term propagated neurospheres derived from the mouse foetal striatum and ventral mesencephalon are capable of rescuing dopaminergic neurons from induced apoptosis and promoting survival in vitro of dopaminergic neurons and in vivo of the nigrostriatal system probably by soluble contact independent factors.

In summary, our data show for the first time that ventral mesencephalic (VM) precursor cells, isolated from porcine embryos 28-30 days of age, can be long-term propagated as neural tissue-spheres (NTS). After more than 230 days, the NTS still form neurons and glia, thus allowing experimental studies of neural precursor cells, their niche and differentiation capacity.

\section{Acknowledgments}

The authors gratefully acknowledge the excellent technical assistance by Dorte Lyholmer, Maibritt Vang Damm, and Randi Godskesen. A special thanks to Annette Møller Dall for providing the photos of embryonic pig brains. This paper was supported by Fonden til Lægevidenskabens Fremme, IMK Almene Fond, the Danish Parkinson Association, the Danish Medical Research Council (J. no. 271-07-0582), the Danish Centre for Stem Cell Research, and the European Science Foundation EUROCORES Programme EuroSTELLS.

\section{References}

[1] W. Dauer and S. Przedborski, "Parkinson's disease: mechanisms and models," Neuron, vol. 39, no. 6, pp. 889-909, 2003.

[2] C. R. Freed, R. E. Breeze, N. L. Rosenberg et al., "Therapeutic effects of human fetal dopamine cells transplanted in a patient with Parkinson's disease," Progress in Brain Research, vol. 82, pp. 715-721, 1990.

[3] C. R. Freed, P. E. Greene, R. E. Breeze et al., "Transplantation of embryonic dopamine neurons for severe Parkinson's disease," The New England Journal of Medicine, vol. 344, no. 10, pp. 710-719, 2001.

[4] P. Brundin, O. Pogarell, P. Hagell et al., "Bilateral caudate and putamen grafts of embryonic mesencephalic tissue treated with lazaroids in Parkinson's disease," Brain, vol. 123, no. 7, pp. 1380-1390, 2000.

[5] A. Björklund, S. B. Dunnett, P. Brundin et al., "Neural transplantation for the treatment of Parkinson's disease," The Lancet Neurology, vol. 2, no. 7, pp. 437-445, 2003.

[6] M. C. Whitman and C. A. Greer, "Adult neurogenesis and the olfactory system," Progress in Neurobiology, vol. 89, no. 2, pp. 162-175, 2009.

[7] D. Ehninger and G. Kempermann, "Neurogenesis in the adult hippocampus," Cell and Tissue Research, vol. 331, no. 1, pp. 243-250, 2008.

[8] L. Studer, V. Tabar, and R. D. G. McKay, “Transplantation of expanded mesencephalic precursors leads to recovery in parkinsonian rats," Nature Neuroscience, vol. 1, no. 4, pp. 290-295, 1998.

[9] P. Jensen, M. Bauer, C. H. Jensen et al., "Expansion and characterization of ventral mesencephalic precursor cells: effect of mitogens and investigation of FAl as a potential dopaminergic marker," Journal of Neuroscience Research, vol. 85, no. 9, pp. 1884-1893, 2007.

[10] A. Storch, G. Paul, M. Csete et al., "Long-term proliferation and dopaminergic differentiation of human mesencephalic neural precursor cells," Experimental Neurology, vol. 170, no. 2, pp. 317-325, 2001.

[11] D. C. Lie, G. Dziewczapolski, A. R. Willhoite, B. K. Kaspar, C. W. Shults, and F. H. Gage, "The adult substantia nigra contains progenitor cells with neurogenic potential," Journal of Neuroscience, vol. 22, no. 15, pp. 6639-6649, 2002.

[12] M. Zhao, S. Momma, K. Delfani et al., "Evidence for neurogenesis in the adult mammalian substantia nigra," Proceedings 
of the National Academy of Sciences of the United States of America, vol. 100, no. 13, pp. 7925-7930, 2003.

[13] H. Frielingsdorf, K. Schwarz, P. Brundin, and P. Mohapel, "No evidence for new dopaminergic neurons in the adult mammalian substantia nigra," Proceedings of the National Academy of Sciences of the United States of America, vol. 101, no. 27, pp. 10177-10182, 2004.

[14] A. Hermann, M. Maisel, F. Wegner et al., "Multipotent neural stem cells from the adult tegmentum with dopaminergic potential develop essential properties of functional neurons," Stem Cells, vol. 24, no. 4, pp. 949-964, 2006.

[15] X. Shan, L. Chi, M. Bishop et al., "Enhanced de novo neurogenesis and dopaminergic neurogenesis in the substantia nigra of 1-methyl-4-phyenyl-1,2,3,6-tetrahydropyridineinduced Parkinson's disease-like mice," Stem Cells, vol. 24, no. 5, pp. 1280-1287, 2006.

[16] E. Arenas, "Towards stem cell replacement therapies for Parkinson's disease," Biochemical and Biophysical Research Communications, vol. 396, no. 1, pp. 152-156, 2010.

[17] R. Wijeyekoon and R. A. Barker, "Cell replacement therapy for Parkinson's disease," Biochimica et Biophysica Acta, vol. 1792, no. 7, pp. 688-702, 2009.

[18] T. Ostenfeld and C. N. Svendsen, "Recent advances in stem cell neurobiology," Advances and Technical Standards in Neurosurgery, vol. 28, pp. 3-89, 2003.

[19] R. K. Andersen, M. Johansen, M. Blaabjerg, J. Zimmer, and M. Meyer, "Neural tissue-spheres: a microexplant culture method for propagation of precursor cells from the rat forebrain subventricular zone," Journal of Neuroscience Methods, vol. 165, no. 1, pp. 55-63, 2007.

[20] R. K. Andersen, J. Zimmer, L. U. Wahlberg, and M. Meyer, "Effect of leukemia inhibitory factor on long-term propagation of precursor cells derived from rat forebrain subventricular zone and ventral mesencephalon," Experimental Neurology, vol. 211, no. 1, pp. 301-310, 2008.

[21] C. N. Svendsen, M. G. Ter Borg, R. J. E. Armstrong et al., "A new method for the rapid and long term growth of human neural precursor cells," Journal of Neuroscience Methods, vol. 85, no. 2, pp. 141-152, 1998.

[22] B. A. Reynolds and S. Weiss, "Generation of neurons and astrocytes from isolated cells of the adult mammalian central nervous system," Science, vol. 255, no. 5052, pp. 17071710, 1992.

[23] K. Chen, T. Baxter, W. M. Muir, M. A. Groenen, and L. B. Schook, "Genetic resources, genome mapping and evolutionary genomics of the pig (Sus scrofa)," International Journal of Biological Sciences, vol. 3, no. 3, pp. 153-165, 2007.

[24] P. Pillay and P. R. Manger, "Order-specific quantitative patterns of cortical gyrification," European Journal of Neuroscience, vol. 25, no. 9, pp. 2705-2712, 2007.

[25] W. G. Pond, S. L. Boleman, M. L. Fiorotto et al., "Perinatal ontogeny of brain growth in the domestic pig," Proceedings of the Society for Experimental Biology and Medicine, vol. 223, no. 1, pp. 102-108, 2000.

[26] A. Villa, E. Y. Snyder, A. Vescovi, and A. Martínez-Serrano, "Establishment and properties of a growth factor-dependent, perpetual neural stem cell line from the human CNS," Experimental Neurology, vol. 161, no. 1, pp. 67-84, 2000.

[27] N. S. Christophersen, X. Meijer, J. R. Jørgensen et al., "Induction of dopaminergic neurons from growth factor expanded neural stem/progenitor cell cultures derived from human first trimester forebrain," Brain Research Bulletin, vol. 70, no. 4-6, pp. 457-466, 2006.
[28] W. Ye, K. Shimamura, J. L. R. Rubenstein, M. A. Hynes, and A. Rosenthal, "FGF and SHH signals control dopaminergic and serotonergic cell fate in the anterior neural plate," Cell, vol. 93, no. 5, pp. 755-766, 1998.

[29] L. Iacovitti and N. D. Stull, "Expression of tyrosine hydroxylase in newly differentiated neurons from a human cell line (hNT)," Neuroreport, vol. 8, no. 6, pp. 1471-1474, 1997.

[30] C. N. Svendsen, D. J. Clarke, A. E. Rosser, and S. B. Dunnett, "Survival and differentiation of rat and human epidermal growth factor-responsive precursor cells following grafting into the lesioned adult central nervous system," Experimental Neurology, vol. 137, no. 2, pp. 376-388, 1996.

[31] W. R. Douglas, "Of pigs and men and research-a review of applications and analogies of the pig, sus scrofa, in human medical research," Space Life Sciences, vol. 3, no. 3, pp. 226234, 1972.

[32] S. A. Book and L. K. Bustad, "The fetal and neonatal pig in biomedical research," Journal of Animal Science, vol. 38, no. 5, pp. 997-1002, 1974.

[33] A. Onishi, M. Iwamoto, T. Akita et al., "Pig cloning by microinjection of fetal fibroblast nuclei," Science, vol. 289, no. 5482, pp. 1188-1190, 2000.

[34] I. A. Polejaeva, S. H. Chen, T. D. Vaught et al., "Cloned pigs produced by nuclear transfer from adult somatic cells," Nature, vol. 407, no. 6800, pp. 86-90, 2000.

[35] J. Betthauser, E. Forsberg, M. Augenstein et al., "Production of cloned pigs from in vitro systems," Nature Biotechnology, vol. 18, no. 10, pp. 1055-1059, 2000.

[36] P. M. Kragh, A. L. Nielsen, J. Li et al., "Hemizygous minipigs produced by random gene insertion and handmade cloning express the Alzheimer's disease-causing dominant mutation APPsw," Transgenic Research, vol. 18, no. 4, pp. 545-558, 2009.

[37] Y. Du, J. Li, P. M. Kragh et al., "Piglets born from vitrified cloned blastocysts produced with a simplified method of delipation and nuclear transfer," Cloning and Stem Cells, vol. 9, no. 4, pp. 469-476, 2007.

[38] M. Mikkelsen, A. MØller, L. H. Jensen, A. Pedersen, J. B. Harajehi, and H. Pakkenberg, "MPTP-induced parkinsonism in minipigs: a behavioral, biochemical, and histological study," Neurotoxicology and Teratology, vol. 21, no. 2, pp. 169-175, 1999.

[39] J. M. Schumacher, S. A. Ellias, E. P. Palmer et al., "Transplantation of embryonic porcine mesencephalic tissue in patients with PD," Neurology, vol. 54, no. 5, pp. 1042-1050, 2000.

[40] T. Deacon, J. Schumacher, J. Dinsmore et al., "Histological evidence of fetal pig neural cell survival after transplantation into a patient with Parkinson's disease," Nature Medicine, vol. 3, no. 3, pp. 350-353, 1997.

[41] G. J. Molenaar, R. I. Hogenesch, M. E. S. Sprengers, and M. J. Staal, "Ontogenesis of embryonic porcine ventral mesencephalon in the perspective of its potential use as a xenograft in Parkinson's disease," Journal of Comparative Neurology, vol. 382, no. 1, pp. 19-28, 1997.

[42] C. W. Olanow, J. H. Kordower, and T. B. Freeman, "Fetal nigral transplantation as a therapy for Parkinson's disease," Trends in Neurosciences, vol. 19, no. 3, pp. 102-109, 1996.

[43] P. M. Almqvist, E. Åkesson, L. U. Wahlberg, H. Pschera, A. Seiger, and E. Sundström, "First trimester development of the human nigrostriatal dopamine system," Experimental Neurology, vol. 139, no. 2, pp. 227-237, 1996.

[44] R. K. Andersen, H. R. Widmer, J. Zimmer, L. U. Wahlberg, and M. Meyer, "Leukemia inhibitory factor favours neurogenic differentiation of long-term propagated human midbrain 
precursor cells," Neuroscience Letters, vol. 464, no. 3, pp. $203-$ 208, 2009.

[45] C. M. Cooper-Kuhn and H. Georg Kuhn, "Is it all DNA repair?: methodological considerations for detecting neurogenesis in the adult brain," Developmental Brain Research, vol. 134, no. 1-2, pp. 13-21, 2002.

[46] N. Osumi, H. Shinohara, K. Numayama-Tsuruta, and M. Maekawa, "Concise review: Pax6 transcription factor contributes to both embryonic and adult neurogenesis as a multifunctional regulator," Stem Cells, vol. 26, no. 7, pp. 16631672, 2008.

[47] C. M. Parras, R. Galli, O. Britz et al., "Mash1 specifies neurons and oligodendrocytes in the postnatal brain," EMBO Journal, vol. 23, no. 22, pp. 4495-4505, 2004.

[48] S. J. Pleasure, A. E. Collins, and D. H. Lowenstein, "Unique expression patterns of cell fate molecules delineate sequential stages of dentate gyrus development," Journal of Neuroscience, vol. 20, no. 16, pp. 6095-6105, 2000.

[49] V. G. Kukekov, E. D. Laywell, O. Suslov et al., "Multipotent stem/progenitor cells with similar properties arise from neurogenic regions of adult human brain," Experimental Neurology, vol. 156, no. 2, pp. 333-344, 1999.

[50] U. Lendahl, L. B. Zimmerman, and R. D. G. McKay, "CNS stem cells express a new class of intermediate filament protein," Cell, vol. 60 , no. 4, pp. 585-595, 1990.

[51] M. Stagaard and K. Mollgard, "The developing neuroepithelium in human embryonic and fetal brain studied with vimentin-immunocytochemistry," Anatomy and Embryology, vol. 180 , no. 1, pp. 17-28, 1989.

[52] F. Doetsch, "The glial identity of neural stem cells," Nature Neuroscience, vol. 6, no. 11, pp. 1127-1134, 2003.

[53] A. D. R. Garcia, N. B. Doan, T. Imura, T. G. Bush, and M. V. Sofroniew, "GFAP-expressing progenitors are the principal source of constitutive neurogenesis in adult mouse forebrain," Nature Neuroscience, vol. 7, no. 11, pp. 1233-1241, 2004.

[54] P. H. Schwartz, P. J. Bryant, T. J. Fuja, H. Su, D. K. O’Dowd, and $\mathrm{H}$. Klassen, "Isolation and characterization of neural progenitor cells from post-mortem human cortex," Journal of Neuroscience Research, vol. 74, no. 6, pp. 838-851, 2003.

[55] A. Keyser, "Basic aspects of development and maturation of the brain: embryological contributions to neuroendocrinology," Psychoneuroendocrinology, vol. 8, no. 2, pp. 157-181, 1983.

[56] H. T. Kim, I. S. Kim, I. S. Lee, J. P. Lee, E. Y. Snyder, and K. In Park, "Human neurospheres derived from the fetal central nervous system are regionally and temporally specified but are not committed," Experimental Neurology, vol. 199, no. 1, pp. 222-235, 2006.

[57] T. D. Palmer, J. Takahashi, and F. H. Gage, "The adult rat hippocampus contains primordial neural stem cells," Molecular and Cellular Neurosciences, vol. 8, no. 6, pp. 389-404, 1996.

[58] P. Jensen, E. G. Pedersen, J. Zimmer, H. R. Widmer, and M. Meyer, "Functional effect of FGF2- and FGF8-expanded ventral mesencephalic precursor cells in a rat model of Parkinson's disease," Brain Research, vol. 1218, pp. 13-20, 2008.

[59] N. D. Stull and L. Iacovitti, "Sonic hedgehog and FGF8: inadequate signals for the differentiation of a dopamine phenotype in mouse and human neurons in culture," Experimental Neurology, vol. 169, no. 1, pp. 36-43, 2001.

[60] L. M. Farkas, N. Dünker, E. Roussa, K. Unsicker, and K. Krieglstein, "Transforming growth factor- $\beta$ s are essential for the development of midbrain dopaminergic neurons in vitro and in vivo," Journal of Neuroscience, vol. 23, no. 12, pp. 5178-5186, 2003.

[61] D. Moses, J. Drago, Y. Teper, I. Gantois, D. I. Finkelstein, and M. K. Horne, "Fetal striatum- and ventral mesencephalonderived expanded neurospheres rescue dopaminergic neurons in vitro and the nigro-striatal system in vivo," Neuroscience, vol. 154, no. 2, pp. 606-620, 2008. 

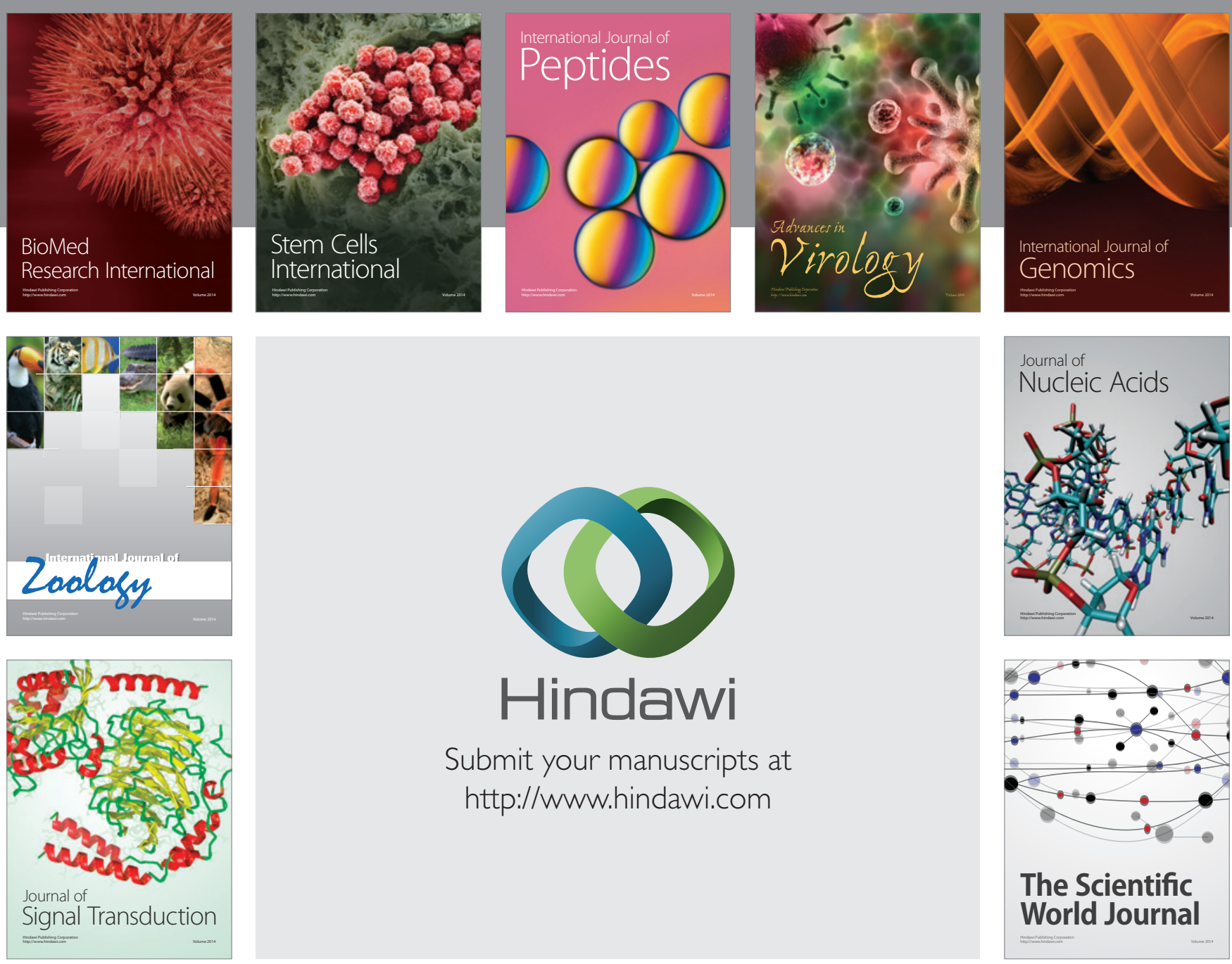

Submit your manuscripts at

http://www.hindawi.com
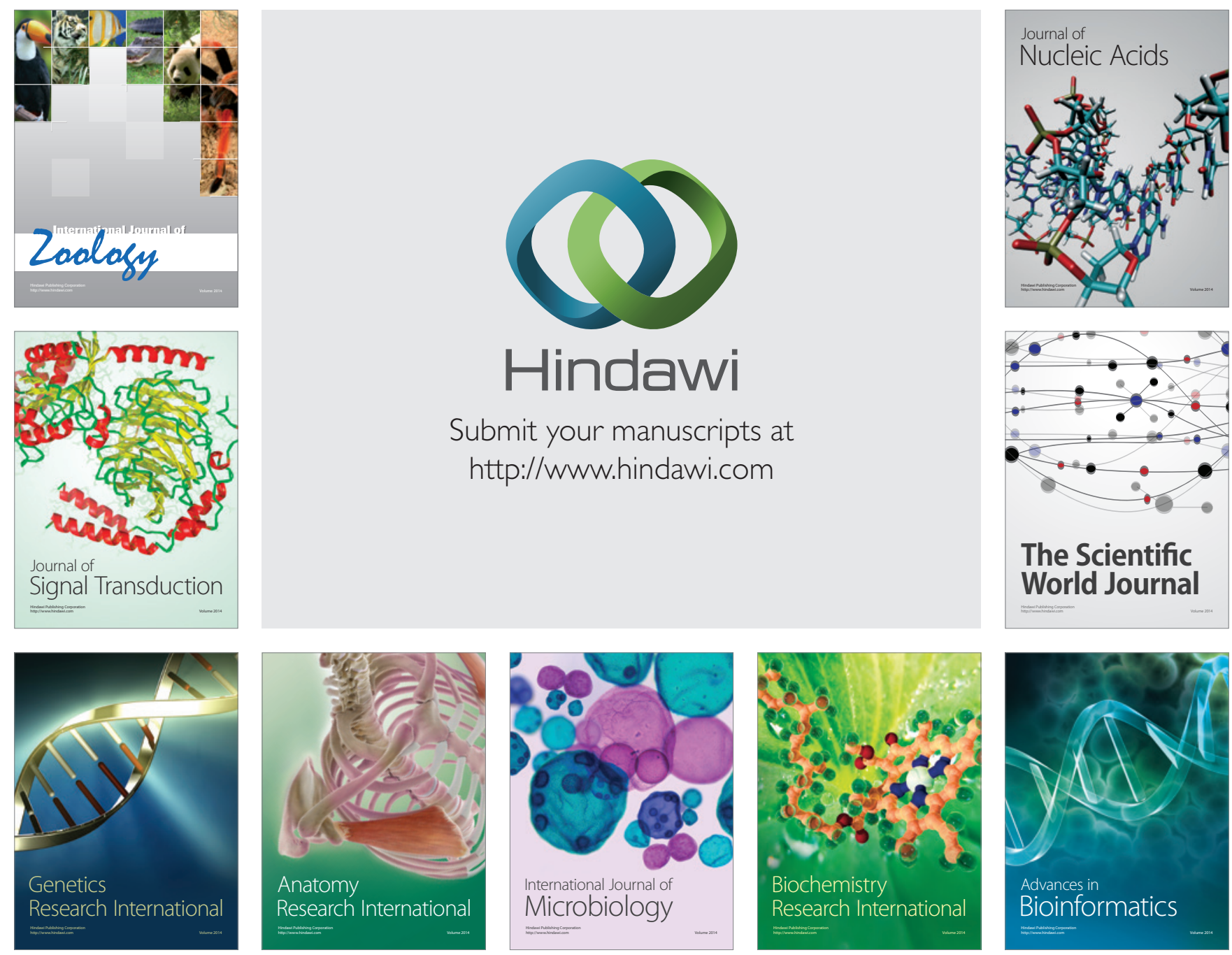

The Scientific World Journal
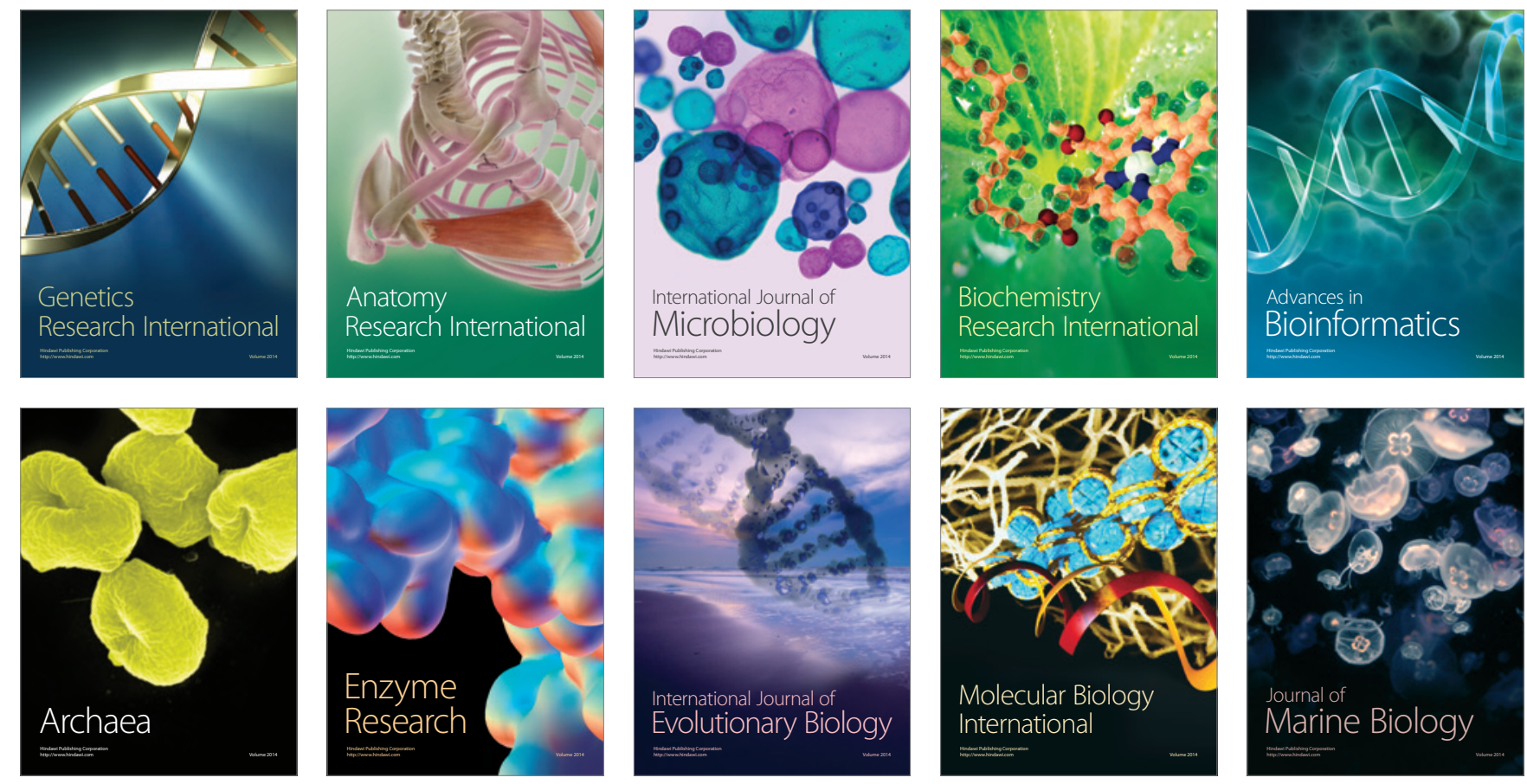